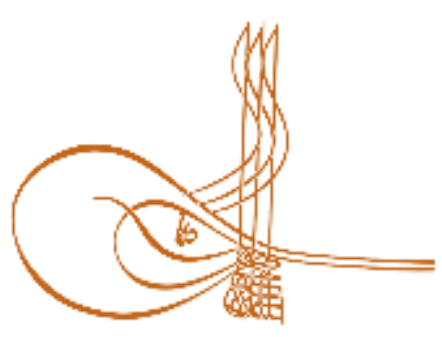

www.turkishstudies.net/social
Turkish Studies - Social Sciences

eISSN: $2667-5617$

Research Article / Araștırma Makalesi

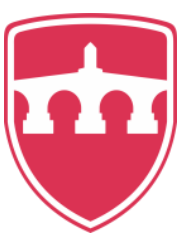

INTERNATIONAL

BALKAN

UNIVERSITY

Sponsored by IBU

\title{
Okul Öncesi Eğitim Kurumlarına Devam Eden Çocukların Katılım Düzeylerinin Farklı Değişkenler Açısından İncelenmesi
}

\author{
Investigation of Children's Involvement Levels Attending Preschool Education in Terms of \\ Different Variables
}

Tuğçe Akyol*

\begin{abstract}
Evaluating the involvement level, which is an important element of development and learning, through objective tools will contribute to determining the factors affecting the involvement levels and to the regulations for increasing these levels. The aim of this research is to examine the involvement levels of 60-72 month-old children attending preschool education in terms of different variables. The population of this research was comprised of 60-72 month-old children, who were attending kindergartens and nursery classes of elementary schools functioning under the Afyonkarahisar Provincial Directorate of National Education in the 2018-2019 academic year. The sample size of the research was determined through maximum variation sampling method, which is one of the purposeful sampling methods, and the sample of the study was comprised of totally 527 children, who were attending kindergartens and nursery classes of elementary schools functioning under the Afyonkarahisar Provincial Directorate of National Education in the 2018-2019 academic year. In the research, the "General Information Form", which was developed by the researcher to collect the demographical information, and the "Leuven Involvement Scale for Young Children", which was used for determining the involvement levels of children, were used. In the analysis of the research data, initially the Kolmogorov-Smirnov (K-S) normality test was applied to determine the groups demonstrating normal distribution. Subsequently, the Mann Whitney U test and Kruskal Wallis- $\mathrm{H}$ test were implemented for examining the intergroup differences that did not demonstrate normal distribution. As the conclusion of the research, it was determined that there was statistically no significant difference among the involvement levels of children concerning gender and number of siblings variables; however, it was determined that there were statistically significant differences among the involvement levels of children concerning the variables of having previous preschool education experience, educational status of the parents, and professions of the parents.
\end{abstract}

Structured Abstract: Introduction Preschool education is important for supporting different developmental areas of children and improving their learning processes. The content of preschool education is dynamic and involves many interaction processes related to learning (Broström, Johansson, Sandberg and Frøkjær, 2014; Shonkoff and Philips, 2000). Learning is achieved through observation, listening, and involvement in the

\footnotetext{
${ }^{*}$ Dr. Öğr. Üyesi, Afyon Kocatepe Üniversitesi, Eğitim Fakültesi, Temel Eğitim Bölümü

Asst. Prof. Dr., Afyon Kocatepe University, Faculty of Education, Department of Basic Education

ORCID 0000-0002-5860-9236

akyol.tugce@gmail.com

Cite as/ Atıf: Akyol, T. (2020). Okul öncesi eğitim kurumlarına devam eden çocukların katılım düzeylerinin farklı

değişkenler açısından incelenmesi, Turkish Studies - Social, $15(2), \quad$ 1-17.
}

https://dx.doi.org/10.29228/TurkishStudies.40067

Received/Geliş: 08 December/Aralık 2019

Checked by plagiarism software

Accepted/Kabul: 25 February/Şubat 2020

Published/Yayın: 29 February/Şubat 2020

Copyright (C INTAC LTD, Turkey

CC BY-NC 4.0 
preschool education period (Rogoff et al., 2003). Laevers (1993) described involvement as an important indicator of the development and learning process and a special mental process that can be observed from infancy to adulthood.

Children, who are highly involved in activities, can fully concentrate, get interested in the process, and have a high motivation. They show their involvement in the process with body language, gestures, and facial expressions, and they enjoy making discoveries (Laevers, 2005b). Indicators of involvement is related to how children concentrate and are influenced by the process, how they involve in the activities and to what extent they fulfill their potentials (Laevers and Declercq, 2018). Concentration, energy, complexity and creativity, facial expression and posture, persistence/standing firm, care, response time, words and satisfaction are reported as the indicators of involvement. Based on these indicators, assessments are conducted concerning the involvement levels of children (Laevers, 1993).

It was reported that evaluating the involvement levels of children is one of the effective ways to determine the nature of the implemented program (Declercq et al., 2011; Laevers, 1997; Raspa, McWilliam and Ridley, 2001). In evaluating involvement levels, children's experiences of a particular event or situation should be taken into account as well as learning environment and learning outcomes (Ebbeck et al., 2012). Evaluating involvement levels in a classroom environment is important for teachers to make the necessary arrangements in learning environments. Additionally, these evaluations allow teachers to identify children's interest in learning environments and to develop their own potential (Laevers, 2011). Evaluating the involvement, which is an important indicator of development and learning process, through objective tools and examining the involvement levels of children in terms of different variables will contribute to the determination of the factors affecting the involvement level and to the arrangements that will improve the involvement levels. Based on these ideas, the aim of this research is to examine the involvement levels of 6072 month-old children, who attend preschool institutions, in terms of different variables.

\section{Method}

The general survey model was used in this research, which aims to examine the involvement levels of 60-72 month-old children, who were attending pre-school education in terms of different variables. In the survey model, a survey is conducted on a group, example or sample in order to reach a general conclusion about the population, which is comprised of numerous elements. (Karasar, 2008).

The population of this research was comprised of 60-72 month-old children, who were attending kindergartens and nursery classes of elementary schools in Afyonkarahisar city center functioning under the Provincial Directorate of National Education. When the demographical properties of the children comprising the research sample were examined, it was determined that $43,3 \%$ were female, $56,7 \%$ were male, $73,4 \%$ had previous preschool education experience, $13,9 \%$ were single child of the family, $71,2 \%$ had two siblings, $15 \%$ had three or more siblings. The mothers of $18 \%$ of the children were graduates of primary schools, those of $21,4 \%$ were graduates of secondary school, while $31,5 \%$ of them were high school graduates, 7,4 \% had associate degrees, 20,7\% had bachelor's degrees, and 5 of them had postgraduate degrees; as per their fathers, $11,8 \%$ were graduates of primary schools, $15 \%$ were graduates of secondary schools, 35,5\% were graduated of high schools, 9,3\% had associate degrees and 25,8\% had bachelor's degrees, while $2,7 \%$ had postgraduate degrees.

In the research, the "General Information Form", which was developed by the researcher to collect the demographical data, and the "Leuven Involvement Scale for Young Children", which was used for determining the involvement levels of children, were used. The data of the research were collected in the 2018-2019 education year within Afyonkarahisar province. In order to collect the research data, initially necessary permissions were obtained from the Afyonkarahisar Provincial Directorate of National Education, and it was implemented in volunteering kindergartens and nursery classes of elementary schools. The researcher observed the children in the sample group during their play times and activity times within their daily education hours. For each child, five observation activities were conducted with time intervals, and the observation results were recorded into the forms prepared for each child.

In the analysis of the data, descriptive statistics such as frequency and percentage were used for evaluating the demographical properties of children. In order to determine whether the scores of children obtained from "Leuven Involvement Scale for Young Children" demonstrate normal distribution, Kolmogorov-Smirnov (K-S) normality test was implemented. Since the values were not normally distributed,

Turkish Studies - Social, 15(2) 
Mann Whitney U test was used for examining the intergroup differences, and Kruskal Wallis-H test was implemented for the differences among three or more groups. While examining the intergroup differences, the significance level was accepted as .05 , and it was reported that if the result is below this level $(p<.05)$ there are intergroup significant differences, while having a result above this level ( $\mathrm{p}>.05)$ indicates that there are no intergroup significant differences (Büyüköztürk et al., 2012).

\section{Findings}

Examining the average scores of the children from the Leuven Involvement Scale for Young Children, it was determined that the average scores of female children was 3, while that of the male children was 2,9, concluding that the involvement level of 60-72 month-old children attending the preschool educational institutions was at a medium level. It was also determined that, concerning the gender variable, there was statistically no significant difference among the average scores of 60-72 month-old children, who were attending preschool educational institutions, obtained from the Leuven Involvement Scale for Young Children. Examining their mean ranks, it was observed that the average score of female children was higher compared to male children.

Concerning the variable of having a previous preschool education experience, it was determined that there was a statistically significant difference among the average scores obtained from the Leuven Involvement Scale for Young Children $(\mathrm{p}<.05)$. It was observed that the average scores of children with a previous preschool education experience was statistically significantly higher compared to those without any previous preschool education experience.

Concerning the number of siblings variable, it was determined that there was statistically no significant difference among their average scores obtained from the Leuven Involvement Scale for Young Children ( $>00.05)$. Examining their mean ranks, it was observed that children with at least two siblings had higher average scores compared to the children who were single child of their parents.

Concerning the educational status of parents variable, it was determined that there was a statistically significant difference among their average scores obtained from the Leuven Involvement Scale for Young Children $(\mathrm{p}<0.05)$. It was determined that the average scores of children, whose fathers and mothers had bachelor's degrees, were statistically significantly higher compared to those, whose mothers and fathers were graduates of primary, secondary, high schools, and with associate degrees.

Concerning the professions of parents variable, it was determined that there was a statistically significant difference among their average scores obtained from the Leuven Involvement Scale for Young Children $(\mathrm{p}<0.05)$. It was observed that the average scores of children, whose mothers were civil servant, were statistically significantly higher compared to the children, whose mothers were self-employed, employee, or housewife; the average scores of children, whose fathers were civil servant, were statistically significantly higher, compared to the children, whose fathers were employee and self-employed.

\section{Conclusions and Suggestions}

As the conclusion of this study, which examines the involvement levels of children attending preschool education in terms of different variables, it was determined that there was statistically no significant difference among the average scores obtained from the Leuven Involvement Scale for Young Children concerning gender and number of siblings variable. As per the variable of having a previous preschool education experience, educational status of parents, and profession of parents, it was determined that there was statistically no significant difference among the average scores obtained from the Leuven Involvement Scale for Young Children, and it was also detected that the involvement levels of children were at a medium level.

In line with the results of this study, following suggestions can be made:

The involvement levels of children attending preschool education institutions can be thoroughly evaluated by different measurement tools such as teacher interview forms, family interview forms to be developed by researchers. Further studies can be planned that will examine the relationships between the involvement levels of children and different variables such as parental attitudes, parent-child communication, professional seniority levels of teachers, classroom management skills, and teacher-child communication. In service trainings can be organized for preschool teachers about observation-based evaluation tools determining the involvement levels of children within the classroom. By preparing new curriculums that

www.turkishstudies.net/social 
include involvement dimensions such as creativity, concentration, and persistence/standing firm, further studies can be implemented examining the effect of this curriculum on the involvement levels of children.

Keywords: Involvement, involvement level, preschool.

Öz: Gelişim ve öğrenme sürecinin önemli bir göstergesi olan katılımın objektif araçlar ile değerlendirilmesi, katılım düzeylerini etkileyen faktörlerin belirlenmesine ve katılım düzeylerinin arttırılması için yapılacak düzenlemelere katkı sağlayacaktır. Bu araştırmanın amacı, okul öncesi eğitim kurumlarına devam eden 60-72 aylık çocukların katılım düzeylerinin farklı değişkenler açısından incelenmesidir. Tarama modelinin kullanıldığı bu araştırmanın çalışma evrenini, 2018-2019 eğitim öğretim yılında Afyonkarahisar il merkezindeki Milli Eğitim Bakanlığı'na bağlı ilkokulların anasınıflarına ve bağımsız anaokullarına devam eden 60-72 aylık çocuklar oluşturmuştur. Araştırmanın örneklem grubu amaçsal örnekleme yöntemlerinden maksimum çeşitlilik örneklemesi ile belirlenmiş olup, araştırmanın örneklemini 2018-2019 eğitim öğretim yılında Afyonkarahisar il merkezindeki Milli Eğitim Bakanlığı'na bağlı ilkokulların anasınıflarına ve bağımsız anaokullarına devam eden toplam 527 çocuk oluşturmuştur. Araştırmada, demografik bilgileri toplamak amacıyla araştırmacı tarafından geliştirilen "Genel Bilgi Formu" ve çocukların katılım düzeylerini belirlemek amacıyla "Leuven Küçük Çocuklar İçin Katılım Ölçeği” kullanılmıştır. Araştırmadan elde edilen verilerin analizinde; Kolmogorov-Smirnoff (K-S) normallik testi sonucunda, normal dağılım göstermeyen gruplarda, gruplar arası farklılık incelenirken Mann Whitney U ve Kruskal Wallis H Testi kullanılmıştır. Araştırma sonucunda, cinsiyet ve kardeş sayısı değişkenlerine göre çocukların katılım düzeyleri arasında anlamlı bir farklılık olmadığı, daha önce okul öncesi eğitim kurumuna devam etme durumu, anne ve babanın öğrenim düzeyi, anne ve babanın meslek durumu değişkenlerine göre çocukların katılım düzeyleri arasında anlamlı bir farklılık olduğu sonucuna ulaşılmıştır.

Anahtar Kelimeler: Katılım, katılım düzeyi, okul öncesi dönem.

\section{Giriş}

Bireylerin belirli yaşam dönemlerinde kazandıkları deneyimler gelişimsel ilerlemeler açısından önem taşımaktadır. Tüm gelişim alanlarında önemli aşamaların görüldüğü, çocukların daha sonraki yaşamlarını etkileyecek bilgi, beceri ve alışkanlıkların kazanıldığı okul öncesi dönem, yaşamın en kritik dönemlerinden biri ve etkili bir zaman dilimi olarak nitelendirilmektedir (Kostelnik, Sodermen ve Whiren, 2004; Oktay, 1999). Bu dönemde, çocukların potansiyellerini en üst düzeyde gerçekleştirebilmeleri için gelişimsel özelliklerinden yola çıkarak gerekli planlamaların yapılması gereklidir (Plaisted, 2008).

Çocukların farklı gelişim alanlarının desteklenmesi ve öğrenme süreçlerinin geliştirilmesi için okul öncesi eğitimin önemi büyüktür. Okul öncesi eğitimin içeriği dinamiktir ve öğrenme ile ilgili birçok etkileşim sürecini içermektedir (Broström, Johansson, Sandberg ve Frøkjær, 2014; Shonkoff ve Philips, 2000). Okul öncesi eğitim programlarının, çocukların gelişimsel özellikleri doğrultusunda çocuk merkezli ve etkin öğrenme ortamlarına önem veren programlar olması gerektiği belirtilmektedir (Aral, Kandır ve Can Yaşar, 2002). Milli Eğitim Bakanlığı Okul Öncesi Eğitim Programı'nda (2013) çocukların etkinliklere aktif bir şekilde katılmaları ve keşfederek öğrenmeleri gerektiği vurgulanmaktadır. Okul öncesi dönemdeki çocuklar zengin uyarıcılar sağlayan, gerçek yaşam için gerekli deneyimler kazanabilecekleri, farklı durumlar ile ilgili gözlemler ve paylaşımlar yapabilecekleri ortamlarda daha rahat öğrenebilmektedirler (Tuğrul, 2012). Okul öncesi dönemde öğrenme, gözlem, dinleme ve katılım yoluyla gerçekleşmektedir (Rogoff ve diğ., 2003). Laevers (1993) katılımı, gelişim ve öğrenme sürecinin önemli bir göstergesi ve bebeklikten yetişkinliğe kadar gözlemlenebilen özel bir zihinsel süreç olarak tanımlamaktadır. Katılım aynı zamanda, çocukların kendi potansiyellerini gerçekleştirdikleri yoğun bir zihinsel etkinlik şeklinde açıklanmaktadır (Laevers, 2005a). Katılım, çocuğun gerçekleştirmekte olduğu aktivitenin bir boyutudur. Bu yüzden katılım, sadece belirli davranışsal özellikler ya da belirli bir alana özgü gelişimsel özellikler doğrultusunda açıklanamaz (Laevers, 2007).

Turkish Studies - Social, 15(2) 
Katılım, çocukların öğrenme sürecindeki deneyimlerini belirleyen değişkenlerden biridir (Laevers, 1997). Ayrıca çocukların içinde bulundukları ortama yüksek düzeyde katılım sağlamaları, öğrenmeye ilişkin duydukları ilginin bir yansıması olarak ifade edilmektedir (Laevers, 1994; Pascal ve Bertram, 1997). Etkinliklere yüksek düzeyde katılım gösteren çocuklar, etkinliğe tamamen konsantre olurlar, sürece ilgi duyarlar ve motivasyonları yüksektir. Beden dili, jest ve mimikleri ile sürece dahil olduklarını gösterirler ve keşifler yapmaktan büyük keyif duyarlar (Laevers, 2005b). Katılımın göstergeleri, çocukların nasıl konsantre oldukları ve süreçten nasıl etkilendikleri, etkinliklerde nasıl yer aldıkları ve kendi potansiyellerini hangi düzeyde gerçekleştirdikleri ile ilgilidir (Laevers ve Declercq, 2018). Konsantrasyon, enerji, karmaşıklık ve yaratıcılık, yüz ifadesi ve duruş, ssrar/vazgeçmeme, özen, tepki süresi, sözler ve doyum katılımın göstergeleri olarak belirtilmektedir. Bu göstergelerden yola çıkılarak çocukların katılım düzeyleri ile ilgili değerlendirmeler yapılmaktadır (Laevers, 1993).

Çocukların katılım düzeylerinin değerlendirilmesinin, uygulanan programın niteliğinin belirlenmesi için kullanılan etkili yollardan biri olduğu belirtilmektedir (Declercq ve diğ., 2011; Laevers, 1997; Raspa, McWilliam ve Ridley, 2001). Katılım düzeylerinin değerlendirilmesinde, öğrenme ortamının ve öğrenme çıktılarının yanısıra çocukların belirli bir olay ya da durumla ilgili deneyimlerinin de dikkate alınması gerekmektedir (Ebbeck ve diğ., 2012). Katılım düzeylerinin sınıf ortamında değerlendirilmesi, öğretmenler tarafından öğrenme ortamlarında gerekli düzenlemelerin yapılabilmesi için önemlidir. Ayrıca yapılan bu değerlendirmeler, çocukların öğrenme ortamlarına ilişkin duydukları ilginin belirlenmesi ve çocukların kendi potansiyellerini geliştirebilmeleri konusunda öğretmenlere olanak tanır (Laevers, 2011). Çocukların davranışsal ve gelişimsel özelliklerinin (González ve dĭğ., 2018; Uren ve Stagnitti, 2009), öğrenme ortamının ve öğretmen-çocuk etkileşiminin (Aydoğan, Farran ve Sağsöz, 2015; Doumen ve diğ., 2012), öğretmenler tarafından gerçekleştirilen planlamaların ve uygulamaların (Laevers ve Declercq, 2011; Leithwood ve Jantzi, 1999; McFadden ve Munns, 2002; Roskos, Burstein ve Keun-You, 2012) çocukların katılımı üzerinde etkili olduğu düşünülmektedir.

Çocukların katılım düzeylerinin ileriki eğitim kademelerinde sahip oldukları akademik başarının önemli bir yordayıcısı olduğu belirtilmektedir (Baloğlu, 2002; Theodotou, 2015). Okul öncesi eğitim kurumlarına devam eden çocukların devam etmeyen çocuklara göre tüm gelişim alanlarında ve öğrenme süreçlerinde görülen önemli aşamalar (Yoshikawa ve diğ., 2013) ve akademik becerilerindeki ve okula hazırbulunuşluk düzeylerindeki olumlu farklılıklar (SirajBlatchford ve diğ., 2008; Tymms, Jones, Albone ve Henderson, 2009) görülmesi, okul öncesi eğitime devam etme süresinin katılım düzeylerini etkileyebileceğini düşündürmektedir. Laevers ve Declercq (2011) tarafindan anaokullarına devam eden çocukların katılım ve duygusal iyi oluşluk düzeylerinin incelendiği araştırmada, okula devam ettikleri süreç boyunca çocukların katılım düzeylerinde bir artış görüldügü sonucuna ulaşılmıştır. Aile katılımının çocukların okula hazırbulunuşluk düzeyleri ve gelişim alanları üzerinde olumlu etkileri olduğu sonuçlarına ulaşılan çalışmalar da görülmektedir (Gozali-Lee ve Mueller, 2010; Lau, Li ve Rao, 2011; Meece, 2013). Ailenin sosyo-ekonomik düzeyini, anne-babanın öğrenim durumu, gelir düzeyi ve mesleki durumları gibi değişkenler belirlemektedir (Gonzalez ve diğ., 2018). Ailenin sosyo-ekonomik düzeyi, çocukların eğitimi için ayrılan kaynakları, nitelikli uyaranlar taşıyan ev ortamı ve çocukların gelişimini destekleme biçimlerini (Shaw ve Shelleby, 2014), anne babanın öğrenim durumu ise ailenin çocuk yetiştirme stilini ve çocuğa yaklaşım biçimini (Shavers, 2007) etkilemektedir. Ailenin sosyo-ekonomik özelliklerinin çocukların gelişimsel özelliklerini ve akademik başarılarını olumlu yönde etkilediğini belirleyen çalışmaların (Eryılmaz, Uladı, Geyik ve Öztürk, 2019; Khanam ve Nghiem, 2016; Kurnaz Adıbatmaz ve Özyürek, 2019) da gerçekleştirildiği görülmektedir. Alanyazında ilkokula ve ortaokula devam eden çocukların katılım düzeylerinin incelendiği (Başal, 2001; Demircan ve Tanrıseven, 2014; Demirezen, Saçlı Uzunöz ve Arslan, 2016; Sarıtepeci ve Yıldız, 2014), okul öncesi dönemdeki çocukların farklı etkinliklere kat1l1m düzeylerini (Baroody ve Diamond, 2013; Bjorgen ve Svendsen, 2015; Roskos, Burstein ve 
Keun-You, 2012; Theodotou, 2015) ve uygulanan programın çocukların katılım düzeyleri üzerindeki etkisini (Akyol ve Erkan, 2018; Declercq ve diğ., 2011; Lenaerts, Braeye, Huong Nguyen, Dang ve Vromant, 2017) ele alan çalışmaların yapıldığı görülmektedir. Ülkemizde okul öncesi dönemdeki çocukların katılım düzeylerinin farklı değişkenler açısından inceleyen araştırmaların ise oldukça sınırlı sayıda olduğu dikkat çekmektedir. Tüm bunlar dikkate alındığında, gelişim ve öğrenme sürecinin önemli bir göstergesi olan katılımın objektif araçlar ile değerlendirilmesi ve çocukların katılım düzeylerinin farklı değişkenler açısından incelenmesi, katılım düzeyini etkileyen faktörlerin belirlenmesine ve katılım düzeylerinin arttırılması için yapılacak düzenlemelere katkı sağlayacaktır. Bu düşüncelerden hareketle, bu araştırmanın amacı okul öncesi eğitim kurumlarına devam eden 60-72 aylık çocukların katılım düzeylerinin farklı değişkenler açısından incelenmesidir. $\mathrm{Bu}$ amaç doğrultusunda aşağıdaki sorulara cevap aranmaktadır:

Okul öncesi eğitim kurumlarına devam eden 60-72 aylık çocukların Leuven Küçük Çocuklar İçin Katılım Ölçeği’nden almış oldukları puan ortalamaları cinsiyetlerine, daha önce okul öncesi eğitim kurumlarına devam etme durumlarına, kardeş sayılarına, anne babaların öğrenim durumlarına ve mesleklerine göre anlamlı bir farklılık var mıdır?

\section{Yöntem}

\section{Araştırma Modeli}

Okul öncesi eğitim kurumlarına devam eden 60-72 aylık çocukların katılım düzeylerinin farklı değişkenler açısından incelenmesini amaçlayan bu araştırmada, genel tarama modeli kullanılmıştır. Tarama modelinde, çok sayıda elemandan oluşan bir evrende, evren hakkında genel bir yargıya varmak için evrenin tümü ya da ondan alınacak bir grup, örnek ya da örneklem üzerinde tarama yapılmaktadır (Karasar, 2008).

\section{Evren ve Örneklem}

Bu araştırmanın evrenini 2018-2019 eğitim öğretim yılında Afyonkarahisar il merkezindeki Milli Eğitim Bakanlığı'na bağlı ilkokulların anasınıflarına ve bağımsız anaokullarına devam eden 60-72 aylık çocuklar oluşturmuştur. Araştırmanın örneklem grubu, amaçsal örnekleme yöntemlerinden maksimum çeşitlilik örneklemesi ile belirlenmiştir. Maksimum çeşitlilik örneklemesi, incelenecek durum ile ilgili benzeşik farklı durumların incelenmesini içerir (Büyüköztürk, Kılıç Çakmak, Akgün, Karadeniz ve Demirel, 2012). Araştırmanın örneklemini ise, 2018-2019 eğitim öğretim yılında Afyonkarahisar il merkezindeki Milli Eğitim Bakanlığı'na bağlı ilkokulların anasınıflarına ve bağımsız anaokullarına devam eden toplam 527 çocuk oluşturmuştur. Araştırmanın örneklemini oluşturan çocukların demografik özellikleri incelendiğinde; \% 43,3 'ünün kı, \%56,7'sinin erkek olduğu, \%73,4'ünün daha önce okul öncesi eğitim kurumuna devam ettiği, \%13,9'unun tek çocuk, \%71,2'sinin iki kardeş, \%15'inin üç ve daha fazla kardeşe sahip oldukları görülmektedir. Çocukların annelerinin \%18'inin ilkokul, \%21,4'ünün ortaokul, \%31,5'inin lise, \%7,4'ünün önlisans, \%20,7'sinın lisans mezunu ve beşinin yüksek lisans mezunu oldukları, babalarının ise \%11,8'inin ilkokul, \%15'inin ortaokul, \%35,5'nin lise, \%9,3'ünün önlisans, $\% 25,8$ 'nin lisans mezunu ve \%2,7'inin ise yüksek lisans mezunu olduğu belirlenmiştir. Ayrıca annelerin \%60,7'sinin ev hanımı, babaların \%29'unun memur olduğu belirlenmiştir.

\section{Veri Toplama Araçları}

Genel bilgi formu: Araştırmacı tarafından geliştirilen formda; çocukların cinsiyeti, yaşı, daha önce okul öncesi eğitim kurmuna devam etme durumu, kardeş sayısı, anne babanın öğrenim durumu ve meslekleri gibi sorulara yer verilmiştir.

Leuven Küçük Çocuklar İçin Katılım Ölçeği: Leuven Küçük Çocuklar İçin Katılım Ölçeği, Laevers tarafından (1994) 3-6 yaş arasındaki çocukların sınıf içindeki etkinliklere katılım düzeylerini belirlemek amacıyla geliştirilmiştir. Bu ölçek, katılım düzeyleri ile ilgili dikkat 
edilmesi gereken özellikler/göstergeler ve katılım düzeyleri olmak üzere toplam iki bölümden oluşmaktadır. Ölçekte çocukların katılım düzeyleri belirlenirken dikkat edilmesi gereken özellikler/göstergeler konsantrasyon, enerji, karmaşıklık ve yaratıcılık, yüz ifadesi ve duruş, 1srar/vazgeçmeme, özen, tepki süresi, sözler ve doyum olarak belirtilmektedir. Kat1lım düzeyleri birden (çok düşük katılım düzeyinden) beşe (çok yüksek katılım düzeyine) kadar derecelendirilmiştir. Zaman aralıklı gözlemler sonucunda ölçekte yer alan özellikler doğrultusunda çocukların katılım düzeyleri belirlenerek gözlem formuna kaydedilmektedir.

Ölçeğin geçerlik ve güvenirlik çalışmaları Akyol ve Erkan (2017) tarafından gerçekleştirilmiş olup, eş gözlemciler arasındaki uyumluluk katsayılarının çok iyi (yeterli) düzeyde olduğu sonucuna ulaşılmıştır. Eş gözlemciler arasındaki uyum Cohen Kappa katsayısı ile belirlenmiş olup, birinci gözlemlerde $(\kappa=0.703, \mathrm{p}<0.05)$; ikinci gözlemlerde $(\kappa=0.755, \mathrm{p}<0.05)$; üçüncü gözlemlerde $(\kappa=0.705, \mathrm{p}<0.05)$; dördüncü gözlemlerde $(\kappa=0.757, \mathrm{p}<0.05)$ ve beşinci gözlemlerde $(\kappa=0.772, \mathrm{p}<0.05)$ olarak hesaplanmıştır.

\section{Veri Toplama Süreci}

Araştırmanın verileri, 2018-2019 eğitim-öğretim yılı Afyonkarahisar ilinde toplanmıştır. Araştırmanın verilerini toplayabilmek amacıyla öncelikle Afyonkarahisar İl Milli Eğitim Müdürlüğünden gerekli izinler alınmış ve araştırmaya katılmaya gönüllü olan anaokullarında ile anasınıflarında gerçekleştirilmiştir. Araştırmacı örneklem grubunda yer alan çocukları, sınıf ortamında günlük eğitim akışındaki oyun ve etkinlik zamanlarında gözlemlemiştir. Her bir çocuğa ait zaman aralıklı beşer gözlem gerçekleştirilmiş olup, gözlem sonuçları her çocuk için düzenlenmiş olan formlara kaydedilmiştir.

\section{Verilerin Analizi}

Elde edilen verilerin analizinde; çocuklara ilişkin demografik özelliklerin değerlendirilmesinde frekans ve yüzde gibi betimsel istatistikler kullanılmıştır. Çocukların Leuven Küçük Çocuklar İçin Katılım Ölçeği'nden aldıkları puanların normal dağılıp dağılmadığını belirlemek amacıyla Kolmogorov-Smirnov (K-S) normallik testi yapılmıştır. Değerlerin normal dağılmaması nedeniyle gruplar arası farklılık incelenirken ikili gruplarda Mann Whitney U Testi, ikiden fazla gruplarda ise Kruskall Wallis-H Testlerinden yararlanılmıştır. Gruplar arası farklılık incelenirken; anlamlılık düzeyi olarak .05 kullanılmış olup $\mathrm{p}<.05$ olması durumunda gruplar arası anlamlı farklılığın olduğu, $\mathrm{p}>.05$ olması durumunda ise gruplar arası anlamlı farklılığın olmadığı belirtilmiştir (Büyüköztürk ve diğ., 2012).

\section{Bulgular}

Araştırmada yer alan çocukların katılım düzeylerinin; cinsiyet, daha önce okul öncesi eğitim kurumlarına devam etme durumlarına, kardeş sayısı, anne-baba öğrenim düzeyi ve annebaba mesleği değişkenlerine ilişkin analiz sonuçları aşağıda tablolar halinde sunulmuştur.

Tablo 1: Çocukların Leuven Küçük Çocuklar İçin Katılım Ölçeği Puan Ortalamalarına İlişkin Sonuçlar

\begin{tabular}{lcccccc}
\hline Cinsiyet & n & Mean & Median & Min. & Max. & ss \\
\hline Kız & 228 & 3,0 & 3,0 & 1,4 & 4,4 &, 6 \\
Erkek & 299 & 2,9 & 3,0 & 1,4 & 4,8 &, 6 \\
\hline
\end{tabular}

Tablo 1 incelendiğinde, Leuven Küçük Çocuklar İçin Katılım Ölçeği puan ortalamalarına bakıldığında, kız çocuklarının puan ortalamaları 3 iken erkek çocuklarının puan ortalamalarının 2,9 olduğu belirlenmiştir. Bu duruma göre, kız ve erkek çocuklarının puan ortalamalarının çok yakın olduğu ve kız ve erkek çocuklarının orta düzeyde bir katılıma sahip oldukları belirlenmiştir. 
Şema 1: Çocukların Leuven Küçük Çocuklar İçin Katılım Ölçeği Puan Ortalamaları

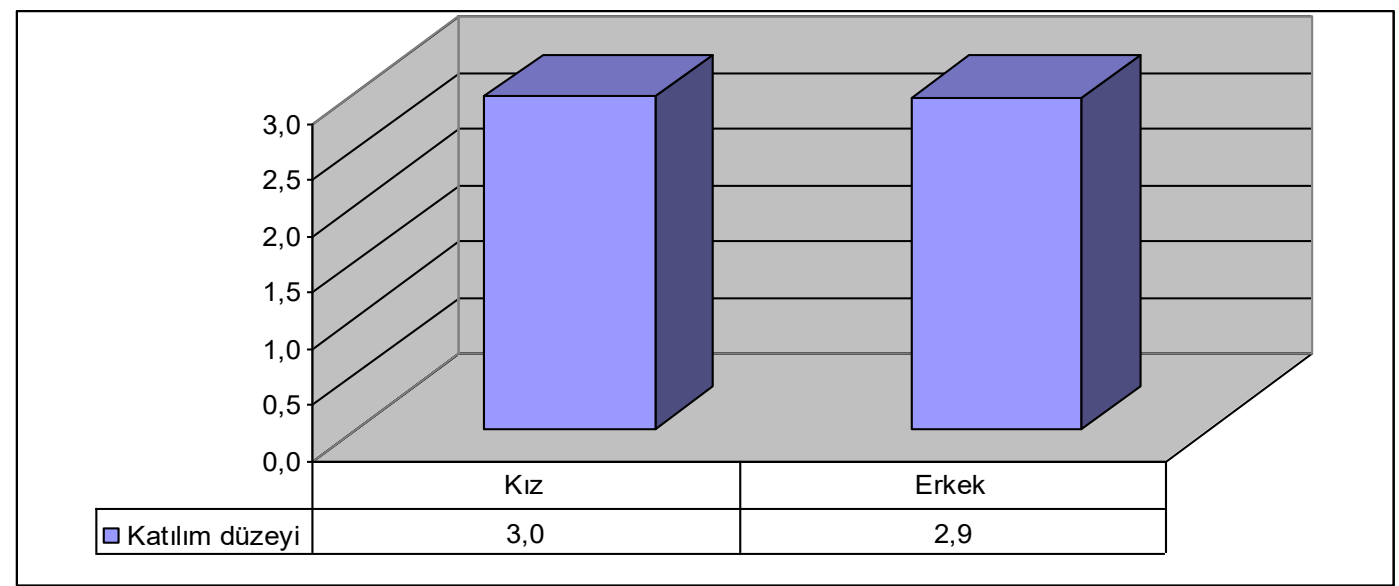

Tablo 2: Çocukların Cinsiyetlerine Göre Leuven Küçük Çocuklar İçin Katılım Ölçeği Puanlarına İlişkin Mann-Whitney U Testi Sonuçları

\begin{tabular}{lcrccccccc}
\hline & & & & \multicolumn{6}{c}{ Mann-Whitney U testi } \\
Cinsiyet & n & Mean & Median & Min. & Max. & ss & Sira Ortalamasi & U & p \\
\hline Kız & 228 & 3,0 & 3,0 & 1,4 & 4,4 &, 6 & 266,5 & & \\
Erkek & 299 & 2,9 & 3,0 & 1,4 & 4,8 &, 6 & 262,1 & 33506,5 & 0,737 \\
Toplam & 527 & 3,0 & 3,0 & 1,4 & 4,8 &, 6 & & & \\
\hline
\end{tabular}

Tablo 2 incelendiğinde, çocukların Leuven Küçük Çocuklar İçin Katılım Ölçeği puan ortalamalarında cinsiyetlerine göre anlamlı farklılık olmadığı görülmektedir $(p>0.05)$. Sira ortalamalarına bakıldığında ise kız çocuklarının puanlarının, erkek çocuklarının puanlarından daha yüksek olduğu görülmektedir. $\mathrm{Bu}$ sonuca göre, çocukların katılım düzeylerinde cinsiyet değişkeninin etkili olmadığ 1 söylenebilir.

Tablo 3: Daha Önce Okul Öncesi Eğitim Kurumuna Devam Etme Durumlarına Göre Leuven Küçük Çocuklar Katılım Ölçeği Puanlarına İlişkin Mann-Whitney U Testi Sonuçları

\begin{tabular}{lccccccccc}
\hline \multirow{2}{*}{$\begin{array}{l}\text { Devam } \\
\text { durumu }\end{array}$} & etme & & & & & \multicolumn{5}{c}{ Mann-Whitney U testi } \\
\hline Gitti & n & Mean & Median & Min. & Max. & ss & Sira Ortalaması & U & p \\
Gitmedi & 387 & 3,0 & 3,0 & 1,4 & 4,8 &, 6 & 283,42 & & \\
Toplam & 140 & 2,7 & 2,8 & 1,4 & 4,2 &, 5 & 210,31 & 19573 & 0,0001 \\
& 527 & 3,0 & 3,0 & 1,4 & 4,8 &, 6 & & & \\
\hline
\end{tabular}

Tablo 3 incelendiğinde, çocukların Leuven Küçük Çocuklar İçin Katılım Ölçeği puan ortalamalarında daha önce okul öncesi eğitim kurumlarına devam etme durumlarına göre anlamlı farkl11ık olduğu görülmektedir $(\mathrm{p}<.05)$. Daha önce okul öncesi eğitim kurumuna devam eden çocukların puanlarının, daha önce okul öncesi eğitim kurumlarına gitmeyen çocuklara göre puanlarından anlamlı derecede yüksek olduğu görülmektedir. Buna göre, çocukların katılım düzeylerinde daha önce okul öncesi eğitim kurumlarına devam etme değişkeninin etkili olduğu düşünülebilir. 
Tablo 4: Kardeş Sayısına Göre Leuven Küçük Çocuklar Katılım Ölçeği Puanlarına İlişkin Kruskall-Wallis H Testi sonuçları

\begin{tabular}{|c|c|c|c|c|c|c|c|c|c|}
\hline \multirow[b]{2}{*}{ Kardeș Sayısı } & \multirow[b]{2}{*}{$\mathbf{n}$} & \multirow[b]{2}{*}{ Mean } & \multirow[b]{2}{*}{ Median } & \multicolumn{6}{|c|}{ Kruskall-Wallis $\mathrm{H}$ testi } \\
\hline & & & & Min. & Max. & Ss & Sira Ort. & $\mathbf{H}$ & $\mathbf{p}$ \\
\hline \multirow{4}{*}{$\begin{array}{l}\text { Tek çocuk } \\
\text { İki kardeş } \\
\text { Üc ve daha fazla } \\
\text { kardeş } \\
\text { Toplam }\end{array}$} & 73 & 2,9 & 2,8 & 1,4 & 4,2 &, 5 & 242,8 & \multirow{4}{*}{1,66} & \multirow{4}{*}{0,435} \\
\hline & 375 & 3,0 & 3,0 & 1,4 & 4,8 & 6 & 267,4 & & \\
\hline & 79 & 3,0 & 3,0 & 1,6 & 4,2 & 6 & 267,5 & & \\
\hline & 527 & 3,0 & 3,0 & 1,4 & 4,8 & 6 & & & \\
\hline
\end{tabular}

Tablo 4 incelendiğinde, çocukların Leuven Küçük Çocuklar İçin Katılım Ölçeği puan ortalamalarında kardeş sayısına göre anlamlı farklılık olmadığ görülmektedir $(p>0.05)$. Sıra ortalamalarına bakıldığında ise iki kardeşi, üç ve üçten fazla kardeşi olan çocukların puan ortalamalarının tek çocuk olanların puan ortalamalarından daha yüksek olduğu görülmektedir. Bu sonuca göre, çocukların katılım düzeylerinde kardeş sayısı değişkeninin etkili olmadığı söylenebilir.

Tablo 5: Anne Öğrenim Düzeyine Göre Leuven Küçük Çocuklar Katılım Ölçeği Puanlarına İlişkin Kruskall-Wallis H Testi sonuçları

\begin{tabular}{|c|c|c|c|c|c|c|c|c|c|c|}
\hline \multirow{2}{*}{$\begin{array}{l}\text { Anne } \\
\text { öğrenim } \\
\text { düzeyi }\end{array}$} & \multirow[b]{2}{*}{$\mathbf{n}$} & \multirow[b]{2}{*}{ Mean } & \multirow[b]{2}{*}{ Median } & \multirow[b]{2}{*}{ Min. } & \multirow[b]{2}{*}{ Max. } & \multirow[b]{2}{*}{ ss } & \multicolumn{4}{|c|}{ Kruskall-Wallis $\mathbf{H}$ testi } \\
\hline & & & & & & & Sira Ort. & $\mathbf{H}$ & $\mathbf{p}$ & İkili Karşılaștırma \\
\hline İlkokul & 95 & 2,9 & 3,0 & 1,6 & 4,2 &, 5 & 253,47 & & & \\
\hline Ortaokul & 113 & 2,8 & 2,8 & 1,4 & 4,4 & 6 & 233,83 & & & \\
\hline Lise & 166 & 2,9 & 2,8 & 1.4 & 4.2 & 6 & 247.67 & & & $5-1$ \\
\hline Önlisans & 30 & 3 & 2,0 & 14 & $\begin{array}{l}42 \\
42\end{array}$ & ${ }^{2}$ & $\begin{array}{l}24,01 \\
30012\end{array}$ & 21,3 & 0,0001 & $5-2$ \\
\hline Lisans ve & 39 & & & & & & 309,12 & & & $5-3$ \\
\hline üsẗ̈ & 114 & 3,2 & 3,2 & 1,6 & 4,8 & 6 & 314,69 & & & $5-4$ \\
\hline Toplam & 527 & 3,0 & 3,0 & 1,4 & 4,8 & 6 & & & & \\
\hline
\end{tabular}

Tablo 5 incelendiğinde, çocukların Leuven Küçük Çocuklar İçin Katılım Ölçeği puan ortalamalarında anne öğrenim düzeylerine göre anlamlı farklılık olduğu görülmektedir $(p<.05)$. Anneleri lisans ve üstü mezunu olan çocukların puan ortalamalarının anneleri önlisans, lise, ortaokul ve ilkokul olan çocukların puan ortalamalarından anlamlı derecede yüksek olduğu görülmektedir. Bu sonuç, çocukların katılım düzeylerinde annelerin öğrenim düzeylerinin etkili olduğu şeklinde açıklanabilir.

Tablo 6: Baba Öğrenim Düzeyine Göre Leuven Küçük Çocuklar Katılım Ölçeği Puanlarına İlişkin Kruskall-Wallis H Testi sonuçları

\begin{tabular}{|c|c|c|c|c|c|c|c|c|c|c|}
\hline \multirow{2}{*}{$\begin{array}{l}\text { Baba } \\
\text { öğrenim } \\
\text { düzeyi }\end{array}$} & \multirow[b]{2}{*}{$\mathbf{n}$} & \multirow[b]{2}{*}{ Mean } & \multirow[b]{2}{*}{ Median } & \multirow[b]{2}{*}{ Min. } & \multirow[b]{2}{*}{ Max. } & \multirow[b]{2}{*}{ ss } & \multicolumn{4}{|c|}{ Kruskall-Wallis $\mathrm{H}$ testi } \\
\hline & & & & & & & Sira Ort. & $\mathbf{H}$ & p & İkili Karșılaștırma \\
\hline İlkokul & 62 & 2,8 & 2,8 & 1,8 & 4,0 &, 5 & 233,3 & & & \\
\hline Ortaokul & 79 & 2,8 & 2,8 & 1,4 & 4,2 & 6 & 218,0 & & & \\
\hline & 187 & 3,0 & 3,0 & 1,4 & 4,4 & 6 & 268,7 & & & $5-1$ \\
\hline Önlisans & 49 & 3,0 & 3,0 & 1,4 & 4,2 & 6 & 286,2 & 14,7 & 0,005 & $5-2$ \\
\hline Lisans ve & 150 & 3,1 & 3,0 & 1,4 & 4,8 & 6 & 290,9 & & & $5-3$ \\
\hline $\begin{array}{l}\text { üstï } \\
\text { Toplam }\end{array}$ & 527 & 3.0 & 3.0 & 1.4 & 4.8 & 6 & 290,9 & & & $5-4$ \\
\hline Toplam & 321 & & & & & & & & & \\
\hline
\end{tabular}

Tablo 6 incelendiğinde, çocukların Leuven Küçük Çocuklar İçin Katılım Ölçeği puan ortalamalarında baba öğrenim düzeylerine göre anlamlı farklılık olduğu görülmektedir $(\mathrm{p}<.05)$. Babaları lisans ve üstü mezunu olan çocukların puan ortalamalarının babaları önlisans, lise, ortaokul ve ilkokul olan çocukların puan ortalamalarından anlamlı derecede yüksek olduğu 
görülmektedir. Buna göre, çocukların katılım düzeylerinde babaların öğrenim düzeylerinin etkili olduğu düşünülebilir.

Tablo 7: Anne Mesleğine Göre Leuven Küçük Çocuklar Katılım Ölçeği Puanlarına İlişkin Kruskall-Wallis H Testi sonuçları

\begin{tabular}{lcccccccccc}
\hline $\begin{array}{l}\text { Anne } \\
\text { meslek }\end{array}$ & n & Mean & Median & Min. & Max. & ss & Sura Ort. & Kruskall-Wallis H testi & p & Ikili Karşılaştırma \\
\hline Evhanımı & 320 & 2,9 & 2,8 & 1,4 & 4,4 &, 6 & 247,2 & & & \\
İşci & 45 & 2,7 & 2,6 & 1,6 & 3,8 &, 6 & 206,5 & & $5-1$ \\
Memur & 105 & 3,2 & 3,2 & 1,4 & 4,8 &, 6 & 322,3 & 28,5 & 0,0001 & $5-2$ \\
Serbest & 57 & 3,1 & 3,0 & 1,4 & 4,2 &, 6 & 296,5 & & & $5-3$ \\
Toplam & 527 & 3,0 & 3,0 & 1,4 & 4,8 &, 6 & & & & $5-4$ \\
\hline
\end{tabular}

Tablo 7 incelendiğinde, çocukların Leuven Küçük Çocuklar İçin Katılım Ölçeği puan ortalamalarında anne mesleğine göre anlamlı farklılık olduğu görülmektedir $(p<.05)$. Anneleri memur olan çocukların anneleri serbest meslek, ev hanımı ve işçi olan çocukların puan ortalamalarından anlamlı derecede yüksek olduğu görülmektedir. Buna göre, çocukların katılım düzeylerinde annelerin mesleklerinin etkili olduğu söylenebilir.

Tablo 8: Baba Mesleğine Göre Leuven Küçük Çocuklar Katılım Ölçeği Puanlarına İlişkin Kruskall-Wallis H Testi sonuçları

\begin{tabular}{lcccccccccc}
\hline $\begin{array}{l}\text { Baba } \\
\text { meslek }\end{array}$ & n & Mean & Median & Min. & Max. & ss & Sira Ort. & H & p & İkili Karşılaştırma \\
\hline İşçi & 140 & 2,8 & 2,8 & 1,6 & 4,4 &, 6 & 219,4 & & & $1-2$ \\
Memur & 155 & 3,1 & 3,0 & 1,4 & 4,8 &, 6 & 287,0 & 16,6 & 0,0001 & $1-3$ \\
Serbest & 232 & 3,0 & 3,0 & 1,4 & 4,2 &, 6 & 273,5 & & & \\
Toplam & 527 & 3,0 & 3,0 & 1,4 & 4,8 &, 6 & & & & \\
\hline
\end{tabular}

Tablo 8 incelendiğinde, çocukların Leuven Küçük Çocuklar İçin Katılım Ölçeği puan ortalamalarında baba mesleğine göre anlamlı farklılık olduğu görülmektedir $(p<.05)$. Babaları memur olan çocukların babaları serbest meslek ve işçi olan çocukların puan ortalamalarından anlamlı derecede yüksek olduğu görülmektedir. $\mathrm{Bu}$ durum, çocukların katılım düzeylerinde babaların mesleklerinin etkili olduğu şeklinde açılanabilir.

\section{Tartışma}

Okul öncesi eğitim kurumlarına devam eden 60-72 aylık çocukların katılım düzeylerinin farklı değişkenler açısından incelenmesini amaçlayan bu araştırmada, kız ve erkek çocuklarının orta düzeyde bir katılıma sahip oldukları belirlenmiştir. Belçika'da 3-12 yaş grubundaki çocukların katılım ve duygusal iyi oluşluk düzeylerinin incelendiği araştırmada, çocukların katılım düzeylerinin orta ve geliştirilebilir düzeyde olduğu sonucuna ulaşılmıştır (Laevers, 2017). Çocukların katılım düzeylerinin geliştirilmesinde, öğrenme ortamında ve öğretmenlerin yapmış oldukları uygulamalarda gerekli düzenlemelerin yapılması gerektiği belirtilmektedir (Laevers, 2011; Roskos, Burstein ve Keun-You, 2012). Bu yüzden günlük eğitim akışında yer alan etkinliklerin konsantrasyon, enerji, karmaşıklık ve yaratıcılık, yüz ifadesi ve duruş, 1srar/vazgeçmeme, özen, tepki süresi, sözler ve doyum gibi boyutları dikkate alan ve çocukların katılım düzeylerini geliştirecek nitelikte olması gerektiği söylenebilir.

$\mathrm{Bu}$ araştırmadan elde edilen bulgulara göre, çocukların Leuven Küçük Çocuklar İçin Katılım Ölçeği puan ortalamalarında cinsiyetlerine göre anlamlı farklılık olmadığı belirlenmiştir. (p>0.05). Theodotou (2015) okul öncesi dönemdeki çocukların okuma yazmaya hazırlık etkinliklerinde katılım düzeylerini incelediği çalışmada, Leuven Küçük Çocuklar İçin Katılım Ölçeği'ni kullanmıştır. Araştırma sonucunda, çocukların katılım düzeylerinde cinsiyet değişkeninin etkili olmadığı belirlemiştir. Çocukların gelişimsel özelliklerinin ve akademik ve dil becerilerinin 
çeşitli değişkenler açısından incelendiği çalışmalarda da cinsiyet değişkeninin etkili olmadığı sonuçlarına ulaşılmıştır (Keleş Ertürk, 2017; Kurnaz Adıbatmaz ve Özyürek, 2019; Ramazan ve Demir, 2011; Uyanık Aktulun, 2019). Katılımın göstergelerinden biri olan yaratıcılık düzeyleri üzerinde cinsiyet değişkenin etkisini inceleyen çalışmalarda da, kız ve erkek çocuklarının yaratıcılık düzeylerinde arasında anlamlı bir farklılık olmadığı sonuçlarına ulaşılmıştır (Can Yaşar ve Aral, 2010; Çeliköz, 2017; Kaufman ve Baer, 2012; Kayıl1, Kuşçu ve Özdemir, 2011).

$\mathrm{Bu}$ araştırmadan elde edilen bulgular doğrultusunda, daha önce okul öncesi eğitim kurumuna devam etme durumuna göre, çocukların Leuven Küçük Çocuklar İçin Katılım Ölçeği'nden aldıkları puan ortalamaları arasında anlamlı bir farklılık olduğu belirlenmiştir $(\mathrm{p}<.05)$. Daha önce okul öncesi eğitim kurumuna devam eden çocukların puan ortalamalarının gitmeyen çocukların puan ortalamalarından anlamlı derecede yüksek olduğu sonucu elde edilmiştir. Bilişsel uyaranlar ile dolu, olumlu deneyimlerin sunulduğu, çocukların bağımsızlık duygusunu destekleyen zengin öğrenme ortamlarının sunulduğu nitelikli bir okul öncesi eğitim çocukların gelişim sürecini olumlu yönde etkilemektedir (Meb, 2013). Ebbeck ve diğ. (2012) tarafindan gerçekleştirilen çalışmada, Singapurda uygulanmakta olan erken çocukluk eğitimi programının etkililiğini belirlemek amacıyla gerçekleştirdikleri araştırmada, Leuven Küçük Çocuklar İçin Katılım Ölçeği ile çocukların katılım düzeylerini incelemişlerdir. Uygulanan program sonrasında çocukların katılım düzeylerinin arttı̆ğ sonucuna ulaşmışlardır. Lenaerts ve diğerleri (2017) Vietnamda süreç odaklı izleme sisteminin etnik açıdan azınlık grupta yer alan çocukların katılım düzeyleri ve duygusal iyi oluşlukları üzerindeki etkisini incelemişlerdir. Okul öncesi öğretmenlerinin mesleki gelişimlerini ele alan eğitim sonrasında sınıflarında çocuk merkezli uygulamalar gerçekleştirdikleri ve düşük düzeyde katılıma sahip olan çocukların katılım düzeylerinin arttığı sonucunu elde etmişlerdir.

$\mathrm{Bu}$ araştırmada yer alan çocukların Leuven Küçük Çocuklar İçin Katılım Ölçeği puan ortalamalarında kardeş sayısına göre anlamlı farklılık olmadığı sonucuna ulaşılmıştır ( $>0.05)$. Eryılmaz, Uladı, Geyik ve Öztürk (2019) tarafindan yapılan çalışmada, 36-72 ay çocukların farklı değiş̧kenlerin alıcı dil becerileri üzerindeki etkisini inceledikleri çalışmada, kardeş sayısının çocukların dil becerileri üzerinde etkili olmadığı sonucuna ulaşmışlardır. Uygun ve Kozikoğlu (2019) yapmış oldukları çalışmada, okul öncesi eğitim kurumlarına devam eden çocukların sosyal yetkinlik davranışlarını incelemişlerdir. Araştırmadan elde edilen bulgular doğrultusunda çocukların sosyal yetkinlik ve kızgınlık-saldırganlık davranışlarının kardeş sayısına göre anlamlı düzeyde farklılaşmadığı sonucunu elde etmişlerdir. Alanyazında kardeş sayısı değişkeninin çocukların sosyal becerileri üzerinde anlamlı farklılık oluşturmadığı sonuçlarına ulaşılan çalışmalar (Elibol Gültekin, 2008; Keçecioğlu, 2015) ve bir yandan dil gelişimi üzerinde anlamlı farklılık oluşturduğu sonuçlarının elde edildiği çalışmalar (Koçak, Ergin ve Yalçın, 2014) görülmektedir. Anne-baba tarafından çocuğa ayrılan nitelikli zamanın çocukların gelişimsel ilerlemeleri ve öğrenme süreçleri üzerinde olumlu etkileri bulunmaktadır. Ailede özellikle büyük kardeş ile geçirilen zamanın ve kazanılan deneyimlerin çocuklara olumlu katkılar sağladığı düşünüldüğünde, aile içindeki birey sayısının bu nitelikli zamanı tek başına etkileyen bir özellik olduğu söylenemez.

$\mathrm{Bu}$ araştırmada anne ve baba öğrenim düzeyi değişkenine göre Leuven Küçük Çocuklar İçin Katılım Ölçeği'nden aldıkları puan ortalamaları arasında anlamlı bir farklılık olduğu belirlenmiştir $(\mathrm{p}<.05)$. Anneleri ve babaları lisans mezunu olan çocukların puan ortalamalarının anneleri ve babaları önlisans, lise, ortaokul ve ilkokul olan çocukların puan ortalamalarından anlamlı derecede yüksek olduğu belirlenmiştir. Senemoğlu (2000) ailenin eğitim düzeyi, mesleki durumu ve çevrenin çocukların bilişsel gelişimini etkilediğini belirtmiştir. Anne babaların öğrenim düzeyleri ile çocuk gelişimi ve eğitimi konusunda gerekli bilgi ve deneyimi kazanmaları arasında bağlantı bulunmaktadır. Ayrıca anne babanın öğrenim düzeyinin yaşam koşulları ve anne baba çocuk etkileşiminin niteliğini olumlu yönde etkilediği düşünülebilir. Alanyazında yapılan çalışmalarda anne ve babanın öğrenim düzeyinin çocuğun bilişsel gelişiminde etkili olduğu sonucuna ulaşılmıştır (Gonzales ve diğ., 2018; Ramazan ve Demir, 2011). Katılımın 
göstergelerinden biri olan yaratıcılık düzeyleri üzerinde anne babanın öğrenim düzeyinin etkisini inceleyen çalışmalarda da, anne babanın öğrenim düzeyinin arttıkça çocukların yaratıcılık düzeylerinin arttığı belirlenmiştir (Can Yaşar ve Aral, 2011; Gizir Ergen ve Köksal Akyol, 2012; Uygun ve Kozikoğlu, 2019).

Anne ve babanın meslek değişkenine göre Leuven Küçük Çocuklar İçin Katılım Ölçeği'nden aldıkları puan ortalamaları arasında anlamlı bir farklılık olduğu $(p<.05)$ bu araştırmadan elde edilen sonuçlar arasındadır. Araştırma sonuçlarına göre, anneleri memur olan çocukların anneleri serbest meslek, işçi ve ev hanımı olan çocukların puan ortalamalarından, babaları memur olan çocukların ise babaları işçi ve serbest meslek olan çocukların puan ortalamalarından anlamlı derecede yüksek olduğu belirlenmiştir. Anne babanın mesleki durumu, ailenin sosyo-ekonomik düzeyini belirleyen etmenler arasındadır. Gelir düzeyi yüksek olan ailelerin, gelir düzeyi düşük olan ailelere göre çocukların gelişimini destekleyici ev ortamını sunabilmelecekleri ve onlara zengin deneyimler kazandırabilecekleri düşünülebilir. Yurtiçinde yapılan çalışmalarda ailenin sosyo-ekonomik düzeyinin çocukların yaratıcılık, bilişsel gelişim, okul olgunluğu düzeylerini olumlu yönde etkilediği sonuçlarına ulaşılmıştır (Can Yaşar ve Aral, 2011; Kayı11, Kuşçu ve Özdemir, 2011; Köşker, 2013; Üstün, Akman ve Etikan, 2004). Yurtdışında gerçekleştirilen çalışmalarda sosyo-ekonomik düzeyin çocukların gelişimlerini olumlu yönde etkilediği belirlenmiştir (Brilli, 2015; Mohsin, Moni, Rahman ve Akhter, 2019). Tüm bu araştırmalardan elde edilen sonuçların, bu çalışmadan elde edilen bulguları destekler nitelikte olduğu görülmektedir.

\section{Sonuç ve Öneriler}

Okul öncesi eğitim kurumlarına devam eden çocukların katılım düzeylerinin farklı değişkenler açısından incelendiği bu araştırma sonucunda, çocukların cinsiyet ve kardeş sayısı değişkenine göre Leuven Küçük Çocuklar İçin Katılım Ölçeği'nden aldıkları puan ortalamaları arasında anlamlı bir farklılık olmadığı belirlenmiştir. Daha önce okul öncesi eğitim kurumuna devam etme durumu, anne ve babanın öğrenim düzeyi, anne ve babanın meslek durumu değişkenlerine göre Leuven Küçük Çocuklar İçin Katılım Ölçeği'nden aldıkları puan ortalamaları arasında anlamlı bir farklılık olduğu ve çocukların orta düzeyde bir katılıma sahip oldukları sonuçlarına ulaşılmıştır.

Çocukların katılım düzeylerinin objektif değerlendirme araçları ile belirlenmesinin önemi göz önünde bulundurularak, okul öncesi eğitim kurumlarına devam eden çocukların katılım düzeyleri araştırmacılar tarafindan geliştirilen öğretmen görüşme formları, aile görüşme formları gibi farklı ölçme araçları geliştirilerek kapsamlı bir şekilde değerlendirilebilir. Ebeveyn tutumları, anne-baba-çocuk iletişimi, öğretmenlerin mesleki kıdemleri, sınıf yönetimi becerileri, öğretmençocuk iletişimi gibi farklı değişkenler ile çocukların katılım düzeyleri arasındaki ilişkiyi inceleyen araştırmalar planlanabilir. Okul öncesi ögretmenlerine çocukların sınıf içindeki katılım düzeylerini belirlemeye yönelik gözleme dayalı değerlendirme araçlarını konu alan hizmet içi eğitimler düzenlenebilir. Yaratıcılık, konsantrasyon, 1srar/vazgeçmeme, gibi katılım boyutlarını kapsayan ele alan eğitim programları hazırlanarak bu programların çocukların katılım düzeyleri üzerindeki etkisini inceleyen çalışmalar yürütülebilir.

\section{Kaynakça}

Akyol, T. ve Erkan, S. (2017). Leuven küçük çocuklar için katılım ölçeği geçerlik ve güvenirlik çalışması. Social Sciences Studies Journal, 3(6), 819-828. http://dx.doi.org/10.26449/sssj.118 
Akyol, T. ve Erkan, S. (2018). Proje yaklaşımına dayalı dayalı eğitimin çocukların katılım düzeylerine etkisi. İşcan, A. (Ed.) Eğitim bilimlerinde örnek araştırmalar (s.279-292). Ankara: Nobel Akademik Yayıncılık.

Aral, N., Kandır, A. ve Can Yaşar, M. (2002). Okul öncesi eğitim ve okul öncesi eğitim programı. İstanbul: Ya-pa Yayınları.

Aydoğan, C., Farran, D.C., \& Sağsöz, G. (2015). The relationship between kindergarten classroom environment and children's engagement. European Early Childhood Education Research Journal, 23(5), 604-618. http://dx.doi.org/10.1080/1350293x.2015.1104036

Baloğlu, N. (2002). Etkili Sınıf Yönetimi. Ankara: Baran Ofset Matbaacılık.

Baroody, E. A., \& Diamond, E. K. (2013). Measures of preschool childrens interest and engagement in literacy activities: Examining gender differences and construct dimensions. Early Childhood Research Quarterly, 28, 291-301. http://dx.doi.org/10.1016/j.ecresq.2012.07.002

Başal, H.A. (2001). Çocuklar için sınıf içi etkinlik ölçeğinin geliştirilmesi, güvenirliği ve geçerliği. Uludă̆ Üniversitesi Eğitim Fakültesi Dergisi, 14(1), 49-64.

Bjørgen, K., \& Svendsen, K. (2015). Kindergarten practitioners' experience of promoting children's involvement in and enjoyment of physically active play: Does the contagion of physical energy affect physically active play? Contemporary Issues in Early Childhood, 16(3), 257-271. http://dx.doi.org/10.1177/1463949115600025

Brilli, Y. (2015). Mother's time allocation, child care and child cognitive development. European University Institute: Max Weber Programme.

Broström, S., Johansson. I., Sandberg, A., \& Frøkjær, T. (2014). Preschool teachers' view on learning in preschool in Sweden and Denmark. European Early Childhood Education Research Journal, 22(5), 590-603. http://dx.doi.org/10.1080/1350293x.2012.746199

Büyüköztürk, Ş., Kılıç-Çakmak, E., Akgün, Ö.E., Karadeniz, Ş., Demirel, F. (2012). Bilimsel araştırma yöntemleri. Ankara: Pegem Akademi.

Can Yaşar, M. ve Aral, N. (2010). Yaratıcı düşünme becerilerinde okul öncesi eğitimin etkisi. Kuramsal Eğitimbilim, 3(2), 201-209.

Can Yaşar, M. ve Aral, N. (2011). Altı yaş çocuklarının yaratıcı düşünme becerilerine sosyo ekonomik düzey ve anne baba öğrenim düzeyinin etkisinin incelenmesi. Kuramsal Ĕ̈itimbilim, 4(1), 137-145.

Çeliköz, N. (2017). Okul öncesi dönem 5-6 yaş çocuklarının yaratıcılık düzeylerinin incelenmesi. Yıldiz Journal of Educational Research, 2(1), 1-25.

Declercq, B., Ebrahim, H., Koen, M., Martin, C., Zyl, E., Daries, G., Olivier, M., Venter, R., Ramabenyane, M., \& Sibeko, L. (2011). Levels of well being and involvement of young children in centre based provision in the free state province of South Africa. South African Journal of Childhood Education, 1(2), 64-80. http://dx.doi.org/10.4102/sajce.v1i2.85

Demircan, Y.S. ve Tanrıseven, I. (2014). 5. Sınıf öğrencilerinin sınıf içi etkinlik ve akademik başarı düzeylerine göre öz-düzenleme stratejileri ve motivasyonel inançlarının incelenmesi. Uluslararası Sosyal Araştırmalar Dergisi, 7(35), 515-535.

Demirezen, İ.K., Saçlı Uzunöz, F. ve Arslan, Y. (2016). İlkokul ve ortaokul öğrencilerinin fiziksel etkinliğe katılım nedenlerinin belirlenmesi: Nevşehir örneği. Gaziantep Üniversitesi Sosyal Bilimler Dergisi, 15(4), 1075-1085. 
Doumen, S., Koomen, M.Y.H., Buyse, E., Wouters, S., \& Verschueren, K. (2012). Teacher and observer views on student-teacher relationships: Convergence across kindergarten relations with student engagement. Journal of School Psychology, 50, 61-76. http://dx.doi.org/10.1016/j.jsp.2011.08.004

Ebbeck, M., Winter, P., Russo, S., Yim, B. Y. H., Teo-Zuzarte, C. L. G. \& Goh, M. (2012). Measuring children's involvement as an indicator of curriculum effectiveness: A curriculum evaluation of a selected child study centre in Singapore. Early Child Development and Care, 182(5), 609-619. http://dx.doi.org/10.1080/03004430.2011.566329

Elibol Gültekin, S. (2008). 5 yaş çocuklarının sosyal becerilerinin bazı değiş̧kenler açısından değerlendirilmesi. Yüksek lisans tezi, Ankara Üniversitesi, Fen Bilimleri Enstitüsü, Ankara.

Eryılmaz, D., Uladı, G., Geyik, M. ve Öztürk, M. (2019). 36-72 aylık çocukların dil gelişim özelliklerinin çeşitli değişkenler bakımından incelenmesi. Karabük Üniversitesi Sosyal Bilimler Enstitüsü Dergisi, 9(1), 265-277. http://dx.doi.org/10.14230/joiss577

Gizir Ergen, Z. \& Köksal Akyol A. (2012). Anaokuluna devam eden çocukların yaratıcılıklarının incelenmesi. Kuramsal Ë̆itimbilim Dergisi, 5(2), 156-170. http://dx.doi.org/10.14230/joiss577

González L., Cortés-Sanchoa, R., Murciaa, M., Ballestera, F., Rebagliato, M., Rodríguez Bernala, C.L. (2018). The role of parental social class, education and unemployment on child cognitive development. Gaceta Sanitaria, November 2018, https://doi.org/10.1016/j.gaceta.2018.07.014 sitesinden alınmıştır. Erişim tarihi: 15.10.2019

Gozali-Lee, E., \& Mueller, D. (2010). Minnessota family literacy and school readiness study: Results through year 2. Minnesota: The Minnesota Early Learning Foundation. http://www.researchconnections.org/childcare/resources/19911 sitesinden alınmıştır. Erişim tarihi: 20.10.2019

Kaufman, J. C., \& Baer, J. (2012). Beyond new and appropriate: Who decides what is creative?. Creativity Research Journal, 24, 83-91. http://dx.doi.org/10.1080/10400419.2012.649237

Kayıll, G., Kuşcu, Ö., \& Özdemir A. (2011). The analysis of creativity of pre-school children in Turkey according to different variants. International Journal of Arts and Sciences, 4(5), 208-218.

Keçecioğlu, Ö. (2015). MEB okul öncesi eğitim programı ve Montesorri yaklaşımına göre eğitim alan 5 yaş çocuklarının sosyal becerilerinin incelenmesi. Yüksek lisans tezi, Marmara Üniversitesi, Eğitim Bilimleri Enstitüsü, İstanbul.

Keleş Ertürk, C. (2017). Beş-altı yaş grubu çocukların okula hazırlık becerilerinin çocuğa, ebeveynlere ve ev ortamına yönelik değişkenler açısından incelenmesi. Yayınlanmamış Yüksek Lisans Tezi. Sosyal Bilimler Enstitüsü, Selçuk Üniversitesi, Konya.

Khanam R., \& Nghiem, S. (2016). Family income and child cognitive and noncognitive development in Australia: Does money matter? Demography, 53, 597-621. http://dx.doi.org/10.1007/s13524-016-0466-x

Koçak, N., Ergin, B. ve Yalçın, H. (2014). 60-72 aylık çocukların Türkçe dil kullanım düzeyleri ve etki eden faktörlerin incelenmesi. KMÜ Sosyal ve Ekonomik Araştırmalar Dergisi, 16 (Özel say1), 100-106. http://dx.doi.org/10.18493/kmusekad.95564

Kostelnik, M. J., Soderman, A. K., \& Whiren, A. P. (2004). Developmentally appropriate curriculum: Best practices in early childhood education (3rd. Ed.). Upper Saddle River, NJ: Pearson Education. 
Köşker, Y. (2013). Köyde ve kentte yaşayan 6 yaş çocukların okul olgunluklarının çeşitli değişkenlere göre incelenmesi. Yüksek Lisans Tezi. Eğitim Bilimleri Enstitüsü, Necmettin Erbakan Üniversitesi, Konya.

Kurnaz Adıbatmaz, F.B. ve Özyürek, A. (2019). Erken çocukluk döneminde gelişimsel değerlendirmenin önemi: Geçda sonuçları örneği. Bingöl Üniversitesi Sosyal Bilimler Enstitüsü Dergisi, 9(18), 1321-1343. http://dx.doi.org/10.29029/busbed.560397

Laevers, F. (1993). Deep level learning. An exemplary application on area of physical knowledge. European Early Childhood Research Journal, 1(1), 53-68. http://dx.doi.org/10.1080/13502939385207351

Laevers, F. (1994). The Leuven Involvement Scale for Young Children, LIS-YC: Manual and video tape. Experiential Education Series No.1. Leuven: Centre for Experiential Education.

Laevers, F. (1997). Assessing the quality of childcare provision: 'Involvement' as criterion. Researching Early Childhood, 3, 151-165.

Laevers, F. (2005a). Sics [Ziko]: Well-Being and involvement in care. Leuven: Kind and Gezin and Research Centre for Experiential Education.

Laevers, F. (2005b). The curriculum as means to raise the quality of Ece. Implications for policy. European Early Childhood Education Research Journal, 13(1), 17-30. http://dx.doi.org/10.1080/13502930585209531

Laevers, F. (2007). Well-being and involvement in care settings. A process-oriented self-evaluation instrument (SiCs). Brussel: Kind \& Gezin.

Laevers, F. (2011). Experiential education: Making care and education more effective through well being and involvement. http://www.childencyclopedia.com/sites/default/files/textesexperts/en/857/experiential-education-makingcare-and-education-more-effective-throughwell-being-and-involvement.pdf sitesinden alınmıştır. Erişim tarihi: 20.10.2019

Laevers, F., \& Declercq, B. (2011). Raising levels of well-being and involvement in Milton Keynes preschool settings (School year 2009-2010). Leuven: CEGO.

Laevers, F. (2017). Monitoring quality in early childhood education and care-approaches and experiences from selected countries. N. Klinkhammer, B. Schäfer, D. Harring, A. Gwinner (Eds.) How are children doing in ECEC? Monitoring quality within a process oriented approach. (ss 178-200). Münich: German Youth Institute.

Laevers, F., \& Declercq, B. (2018). How well-being and involvement fit into the commitment to children's rights. European Journal of Education, 53, 325-335. http://dx.doi.org/10.1111/ejed.12286

Lau, E.Y.H., Li, H., \& Rao, N. (2011). Parental involvement and children's readiness for school in China. Educational Research, 53(1), 95-113. http://dx.doi.org/10.1080/00131881.2011.552243

Leithwood, K., \& Jantzi, D. (1999). The relative effects of principal and teacher sources of leadership on student engagement with school. Educational Administration Quarterly, 35(5), 679-706. http://dx.doi.org/10.1080/00131881.2011.552243

Lenaerts, F., Braeye, S., Huong Nguyen, L.T., Dang, A.T., \& Vromant, N. (2017). Supporting teachers in Vietnam to monitor preschool children's wellbeing and involvement in preschool classrooms. International Journal of Early Childhood, 49, 245-262. http://dx.doi.org/10.1007/s13158-017-0188-2 
McFadden, M., \& Munns, G. (2002). Student engagement and the social relations of pedagogy. British Journal of Sociology of Education, 23(3), 357-366. http://dx.doi.org/10.1080/0142569022000015409

Meece, D. (2013). Resident father-child involvement: Associations with young children's social development and kindergarten readiness in the ECLS-B. Research report from University of Tennessee at Chattanooga, School of Education. http://files.eric.ed.gov/fulltext/ED542612.pdf sitesinden indirilmiştir. Erişim tarihi: 15.10.2019

Mohsin, K.F., Moni, N.N., Rahman, R., \& Akhter, F. (2019). Impact of mother employment on child development: study in Khulna city of Bangladesh. IOSR Journal of Humanities And Social Science (IOSR-JHSS) 24(4), Ser. 2 (April. 2019), 25-38.

Oktay, A. (1999). Yaşamın sihirli yılları. İstanbul: Epsilon.

Pascal, C., \& Bertram, A.D. (1997). Effective early learning: Case studies in improvement. London: Hodder \& Stoughton.

Plaisted, L. L. (2008). Early education of children. Los Angles: BiblioBazaar.

Ramazan, O. ve Demir, S. (2011). Okul öncesi eğitim kurumuna devam eden 36-48 aylık çocukların bilişsel gelişim düzeyleri. Eğitim Bilimleri Araştırmaları Dergisi, 1(2), 83-98.

Raspa, M. J., McWilliam, R. A., \& Ridley, S. M. (2001). Child care quality and children's engagement. Early Education and Development, 12, 209-224. http://dx.doi.org/10.1207/s15566935eed1202_3

Ridley, S.M., McWilliam, R. A., \& Oates, C.S. (2000). Observed engagement as an indicator of child care program quality. Early Education and Development, 11(2), 133-146. http://dx.doi.org/10.1207/s15566935eed1102_1

Rogoff, B., Paradise, R., Arauz, R. M., Correa-Chávez, M., \& Angelillo, C. (2003). Firsthand learning through intent participation. Annual Review of Psychology, 54, 175-203. http://dx.doi.org/10.14417/ap.126

Roskos, K., Burstein, K., \& Keun-You, B. (2012). A typology for observing children's engagement with ebooks at preschool. Journal of Interactive Online Learning, 11(2), 47-66. http://dx.doi.org/10.1080/09669760.2012.743098

Sarıtepeci, M. ve Yıldız, H. (2014). Harmanlanmış öğrenme ortamlarının öğrencilerin derse katılım ve derse karşı motivasyonları üzerine etkisinin incelenmesi. Kırşehir Eğitim Fakültesi Dergisi, 15(1), 211-223.

Senemoğlu, N. (2000). İlk çocukluk döneminde gelişim. Çocuk gelişimi ve psikolojisi. (Edt: E. Ceyhan). Eskişehir: Anadolu Üniversitesi Yayınları.

Shavers V.L. (2007). Measurement of socioeconomic status in health disparities research. J Natl Med Assoc. 99, 1013.

Shaw, D.S., \& Shelleby, E.C. (2014). Early-starting conduct problems: Intersection of conduct problems and poverty. Annu Rev Clin Psychol, 10, 503-528. http://dx.doi.org/10.1146/annurev-clinpsy-032813-153650

Shonkoff, J., \& Phillips, D. (2000). From neurons to neighborhoods: The science of early childhood development. Washington D.C: National Academy Press. 
Siraj-Blatchford, I., Taggart, B., Sylva, K., Sammons, P., \& Melhuish, E. (2008). Towards the transformation of practice in early childhood education: The effective provision of preschool education (EPPE) project. Cambridge Journal of Education, 38(1), 23-36.

Theodotou, E. (2015). Can we play again with Picasso miss? The effects of the arts in children's involvement during literacy activities in the early years settings: A case study in the Greek context. 3rd International Academic Conference on Social Sciences, 25-26 Temmuz 2015, İstanbul.

Tuğrul, B. (2012). Oyun temelli öğrenme, R. Zembat (Ed.). Okul öncesinde özel ögrretim yöntemleri (ss 187-220). Ankara: Anı Yayınc1lik.

Tymms, P., Jones, P., Albone, S., \& Henderson, B. (2009). The first seven years at school. Educational Assessment, Evaluation and Accountability, 21(1), 67-80. http://dx.doi.org/10.1007/s11092-008-9066-7

Uren, N., \& Stagnitti, K. (2009). Play, social competence and involvement in children aged 5-7 years: The concurrent validity of the child-initiated pretend play assessment. Australian Occupational Therapy Journal, 56, 33-40. http://dx.doi.org/10.1111/j.14401630.2008.00761.x

Uyanık Aktulun, Ö. (2019). 60-72 aylık çocukların erken akademik ve dil becerilerinin çeşitli değişkenler açısından incelenmesi. Turkish Studies, 14(1), 775-797. http://dx.doi.org/10.7827/turkishstudies.14776

Uygun, N. ve Kozikoğlu, İ. (2019). Okul öncesi eğitim kurumlarına devam eden çocukların sosyal yetkinlik davranışlarının incelenmesi. Ege Eğitim Dergisi, 20(1), 305-321. http://dx.doi.org/10.12984/egeefd.526276

Üstün, E., Akman, B. \& Etikan, İ. (2004). Farklı sosyo-ekonomik düzeydeki çocukların bilişsel gelişimlerinin değerlendirilmesi. Hacettepe Üniversitesi Eğitim Fakültesi Dergisi, 26, 205210 .

Yoshikawa, H., Weiland, C., Brooks-Gunn, J., Burchinal, M., Espinosa, L., Gormley, W.T., Ludwig, J., Magnuson, K., Phillips, D., \& Zaslow, M. (2013). Investing in our future: The evidence base on preschool education. http://fcd-us.org/resources/evidence-base preschool sitesinden indirilmiştir. Erişim tarihi:22.11.2019 